\title{
SLOVAK-ENGLISH VOCALIC APPROXIMATION
}

The article is focused on the quality of English pronunciation of Slovak native speakers reflected in the formant structure of their short English vowels compared to the reference formant values of short English and Slovak vowels. The primary objective is to detect the level of phonic approximation within the system of English short vowels.

Key words: Pronunciation. Slovak. English. Short vowels.

\section{Introduction}

Besides the dominating behaviorist and structuralist theories of the Second Language Acquisition a new concept of the second language (L2) acquisition was formulated in the 1960s - the theory of interlanguage [1-5]. Some other names used for the interlanguage phenomenon are: transitive competence [1], approximative system [4], idiosyncratic dialect [6], multicompetence [7], transmitting or the third system [8].

The theory of interlanguage considers a foreign language competence to be a process of an autonomous language code creation which gradually (successively or continually) approximates to the foreign language quality in the process of qualitative and quantitative improvement [9]. Thus the interlanguage is a synchronic profile of a diachronic process of L2 acquisition/learning.

Interlanguage (current language competence of an individual) has some features of an idiolect and a dynamic character, therefore a mistake is considered part of language development [10]. Ideally, the interlanguage consists of less and less features of the mother tongue (L1) and of more and more features of the foreign language. The transitive intercode should reflect the potential quality of a L2 competence in $1-100 \%$ interval [8]. But, in fact, stagnation and fossilization are much more frequent.

Early trends in the Second Language Acquisition research considered mistake a negative phenomenon and the L2 sounds produced by a non-native speaker were evaluated as correct or incorrect discrete entities. Today, mistakes are thought as a continuum of approximations towards L2 sounds which is influenced by the current language competence more than by the language interference [11].

The Phonological Translation Hypothesis [12] analogically claims that the dominance of $\mathrm{L} 1$ sound system is a more probable reason of non-authentic L2 pronunciation than restrictions resulting from the neuro-physiological maturity of an individual. The Upper Limit/Level Hypothesis [13] similarly says that there exists a maximum limit of similar L1 and L2 sounds approximation, where the speakers mix L1 and L2 quality of phones (Merger Hypothesis) [14], but usually do not reach the authentic pronunciation of a native speaker.

Apart from the presupposition that each non-native speaker has an upper limit of approximation to the target level of pronunciation [13], some experiments [14-16] proved the possibility of continuous improvement in L2 phonic competence. Thus the phonetic categories should be gradually optimized and created before the equivalent phonological categories are created. According to L. J. Dickerson [16] the most significant pronunciation deviations are being eliminated first in this process. The close approximations seem to be the most persistent ones. According to the theory of language interference [17], the interlingual identification of sounds significantly contributes to the upper limit of approximation.

Phonological differences between L1 and L2 are not the only ones (or the most important) determinants of $\mathrm{L} 2$ sound production quality. The learners must acquire a new complex of articulatory gestures and modify the existing phonetic models, while they often produce the scale of sound variants for one phoneme - a continuum of approximations to the prototype L2 sounds. The phonic interference thus inhibits the approximation to the target system via similarity and difference of elements. The interference is one of the interlanguage phenomena and one, but not the only, reason of non-authentic L2 pronunciation.

\section{Methodology}

We focused on the quality of English pronunciation of Slovak speakers and its reflection in the formant structure of short vowels.

\footnotetext{
* Zdena Kralova ${ }^{1}$, Julius Zimmermann ${ }^{2}$

${ }^{1}$ Department of English Language and Literature, Faculty of Humanities, University of Zilina, Slovakia; zdena.kralova@fpv.uniza.sk

${ }^{2}$ Department of Slovak Studies, Slavonic Philologies, and Communication, Faculty of Arts, P. J. Safarik University in Kosice, Slovakia
} 
Our primary objective was to detect the level of the qualitative approximation of the short English vowels produced by Slovak speakers to the English reference values. The Slovak language is considered primary, native, dominant and interfering system (L1) and the English language is the secondary, non-native, non-dominant, interfered system (L2). We recorded spontaneous English monologues of the Slovak speakers. Then we segmented short English vowels from each text and we experimentally analyzed the values of the first and the second formants of seven short English vowels. Then we statistically compared the detected $\mathrm{F} 1$ a F2 values and the reference values of the given vowels mentioned in the relevant phonetic publications $[18,19]$ for the phonic approximation.

\section{Subjects}

We worked with the group of 40 Year 1 students (30 female, 10 male) all enrolled in the study program of English Language and Literature at the Faculty of Humanities, University of Zilina, Slovakia. The average age of the respondents was 19 , they all were of Slovak nationality, their mother tongue was Slovak and they all reported normal hearing dispositions. Their average English lexical and grammatical competence was at B1 and B2 levels of the Common European Framework of Reference for Languages (CEFR) [20]. Most of them started learning English at the first level of elementary school with a non-native English teacher. Most of them have never stayed in an English-speaking country for a longer period.

\section{Material}

The recordings of the English monologues of each of the 40 respondents (average length 3.8 minutes) were the basic research material. To maintain a similar lexis and style of the respondents' utterances we chose an autobiographical topic. We considered spontaneous speech more natural than reading isolated lexical units. Though the canonic (non-coarticulated) form of vowels is the most suitable for the experimental analysis, we tried to simulate the real L2 performance in which the speaker concentrates more on the content than on its phonetic form. The dialogue with a native speaker would have corresponded with real communication better, but for the practical reasons we chose a one-way type of communication.

Because of the great formant variation of each individual and a relatively high contextual variability (transgresivity) of vowels it was necessary to respect the specificity of the speaker and to define the resulting data according to several measurements of several speakers. Concerning the type of text it was not always possible to keep the context compatibility and the preceding and following segmental environment in all analyzed units [e.g., 21]. The input data for the experimental analysis were segmented from the corpus of spoken texts in English. We selected each of the seven short English vowels $|I|,|e|,|\omega|,|\Lambda /|, D /, / \mathrm{\nu} /, / \partial /$ in five different manifestations from each text.

\section{Procedure}

a) We recorded the spontaneous English monologues of each respondent using a condenser microphone. b) We segmented the short vowels from the texts.

c) The segments were experimentally analyzed in the Speech Analyzer system

d) The results of the experimental analysis were statistically analyzed.

\section{Results}

We chose the formants of short English vowels as the locus of the English phonic competence dynamics. The selected segments were experimentally analyzed, in the Speech Analyzer program (Version 2.7) SIL International. JAARS - ITS, Waxhaw, NC.

The units of the corpus were analyzed by oscillography, spectrography and spectral analysis. In our phonetic research we applied the following procedure:

a) we displayed an oscillogram, wide-band sonagram and LPC spectrum in the Speech Analyzer program (Figure 1);

b) we marked the place in the given oscillogram, where the biggest alternation of the amplitude, frequency and acoustic wave was observed and we manually segmented the given segment via audio-correlation and visual-correlation methods;

c) we made a spectral analysis of the given segment and we read $\mathrm{F} 1$ and $\mathrm{F} 2$ from the LPC spectrum;

d) we calculated the mean values from the five measured F1 a F2 values of each analyzed sound of each respondent.

The data from the experimental analysis were statistically characterized by the parameters of position and parameters of variability (Table 3).

\section{Parameters of position:}

$\bar{x} \quad$ - arithmetic average of the data (mean);

$\tilde{x}$ - median (medium value, which divides the statistical set into two equal parts);

Parameters of variability:

$\sigma_{x}$ - standard deviation (absolute measure of variability);

$V_{x}$ - variation coefficient (relative measure of variability).

Vowels are acoustically characterized by spectral areas defined by the relations of formant frequencies in two-dimensional (F1/F2) spectral structure in $\mathrm{Hz}$. Their mutual articulatory and acoustic discreteness is lower than that of the consonants. The variation interval of the formants is rather big. A person is not able to create an absolutely identical articulatory position twice and the variance also depends on the characteristics of the neighbouring sounds.

The mean values of the formants of the English vowels produced by the respondents (A) are shown in Table 3. When displaying the vowels in the formant scheme the average values of formants are used. The variation of formant values was rather low (under 50\%) except F2 [D] $(\mathrm{Vx}=55 \%)$. The reference values of the English $\left(A^{0}\right)$ and Slovak $\left(S^{0}\right)$ vowels used are cited from relevant linguistic publications [18, p. 100; 19, pp. 204-209] and are shown in Table 2. 


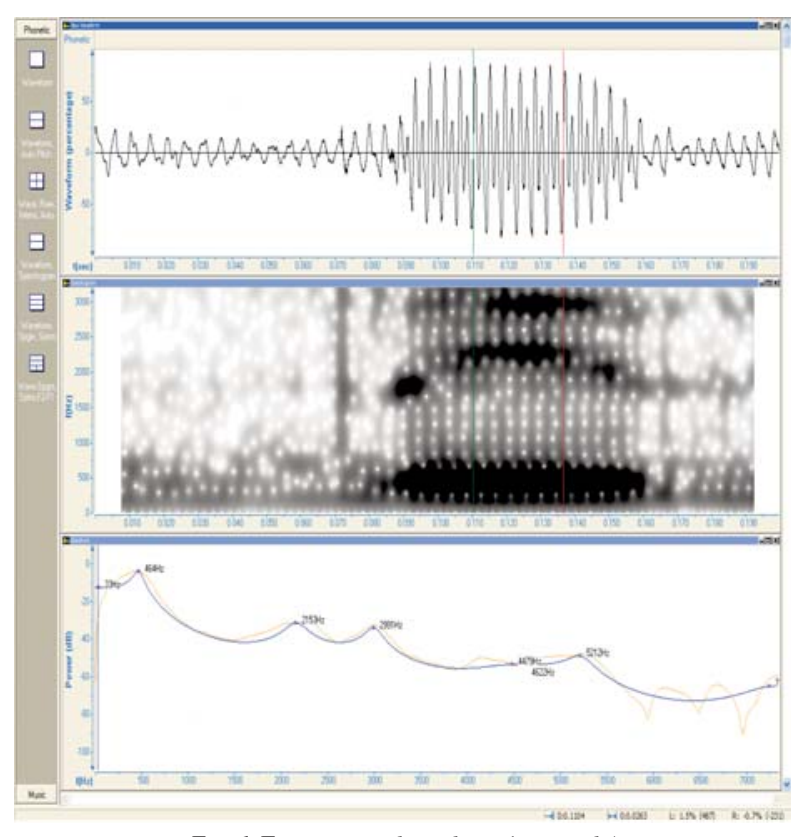

Fig. 1 Experimental analysis (a sample)

We observed a higher approximation of the produced vowels to the Slovak reference values than to the English reference values which can be seen in the formant scheme (Fig. 2). This is an obvious and expected result. The Slovak language as the dominant system significantly influences the production of the secondary (English) system elements. The interlanguage interference, especially at the intermediate level of L2 competence, is the dominant feature of the whole L2 performance.

System of Slovak and English short vowels

Table 1

\begin{tabular}{|c|c|c|c|}
\hline & Front & Central & Back \\
\hline High & $|i|,|I|$ & & $|u|,|\mathrm{v}|$ \\
\hline Mid & $|e|,|e|$ & $|\partial|$ & $|o|$ \\
\hline Low & $|e|$ & $|\ddot{a}|,|a|,|\Lambda|$ & $|D|$ \\
\hline
\end{tabular}

Reference values of $F_{1}$ and $F_{2}$

Table 2

\begin{tabular}{|c|c|c|c|c|c|c|c|}
\hline$S^{0}$ & $\mathrm{~F}_{1}$ & $\mathrm{~F}_{2}$ & $\mathrm{~F}_{3}$ & $A^{0}$ & $\mathrm{~F}_{1}$ & $\mathrm{~F}_{2}$ & $\mathrm{~F}_{3}$ \\
\hline$|i|$ & 280 & 1916 & 2656 & $|I|$ & 360 & 2220 & 2960 \\
\hline$|e|$ & 452 & 1718 & 2365 & $|e|$ & 600 & 2060 & 2840 \\
\hline$|a|$ & 700 & 1510 & 2300 & $|a|$ & 800 & 1760 & 2500 \\
\hline$|a|$ & 682 & 1315 & 2293 & $|\Lambda|$ & 760 & 1320 & 2500 \\
\hline$|0|$ & 481 & 1084 & 2194 & $|D|$ & 560 & 920 & 2560 \\
\hline$|u|$ & 326 & 967 & 2059 & $|v|$ & 380 & 940 & 2300 \\
\hline & & & & $/ \partial \mid$ & 560 & 1480 & 2520 \\
\hline
\end{tabular}

\begin{tabular}{|c|c|c|c|c|c|c|c|c|c|c|c|c|c|c|}
\hline \multirow{2}{*}{ A } & \multicolumn{2}{|c|}{$|I|$} & \multicolumn{2}{|c|}{$|e|$} & \multicolumn{2}{|c|}{$|a|$} & \multicolumn{2}{|c|}{$|\Lambda|$} & \multicolumn{2}{|c|}{$|D|$} & \multicolumn{2}{|c|}{$|v|$} & \multicolumn{2}{|c|}{$|\partial|$} \\
\hline & $\mathrm{F}_{1}$ & $\mathrm{~F}_{2}$ & $\mathrm{~F}_{1}$ & $\mathrm{~F}_{2}$ & $\mathrm{~F}_{1}$ & $\mathrm{~F}_{2}$ & $\mathrm{~F}_{1}$ & $\mathrm{~F}_{2}$ & $\mathrm{~F}_{1}$ & $\mathrm{~F}_{2}$ & $\mathrm{~F}_{1}$ & $\mathrm{~F}_{2}$ & $\mathrm{~F}_{1}$ & $\mathrm{~F}_{2}$ \\
\hline 1 & 308 & 1492 & 355 & 1702 & 689 & 1666 & 779 & 966 & 407 & 1009 & 281 & 982 & 301 & 1615 \\
\hline 2 & 257 & 2279 & 478 & 2055 & 723 & 1680 & 793 & 1432 & 426 & 1296 & 368 & 1233 & 732 & 2003 \\
\hline 3 & 253 & 1789 & 329 & 1838 & 495 & 1270 & 365 & 912 & 492 & 1091 & 318 & 1118 & 517 & 1227 \\
\hline 4 & 306 & 2369 & 507 & 1995 & 388 & 1258 & 511 & 1478 & 388 & 1186 & 450 & 877 & 457 & 1873 \\
\hline 5 & 318 & 2348 & 505 & 1938 & 989 & 1566 & 563 & 1430 & 457 & 1009 & 353 & 809 & 581 & 1744 \\
\hline 6 & 264 & 1854 & 386 & 1943 & 668 & 1446 & 758 & 1497 & 381 & 963 & 465 & 882 & 397 & 1766 \\
\hline 7 & 323 & 1456 & 518 & 1692 & 689 & 1593 & 904 & 1430 & 421 & 1570 & 486 & 914 & 711 & 2110 \\
\hline 8 & 323 & 1310 & 410 & 2151 & 775 & 1744 & 806 & 1370 & 632 & 1197 & 409 & 1133 & 497 & 1830 \\
\hline 9 & 235 & 1780 & 458 & 1689 & 474 & 1572 & 891 & 1357 & 721 & 1589 & 480 & 831 & 732 & 1852 \\
\hline 10 & 234 & 2052 & 399 & 1157 & 495 & 1462 & 409 & 1379 & 571 & 981 & 366 & 790 & 366 & 926 \\
\hline 11 & 283 & 1922 & 492 & 2133 & 797 & 1465 & 493 & 1138 & 651 & 861 & 317 & 903 & 454 & 2175 \\
\hline 12 & 377 & 2098 & 372 & 1562 & 603 & 1400 & 507 & 1745 & 633 & 993 & 297 & 676 & 475 & 2369 \\
\hline 13 & 314 & 2345 & 513 & 2028 & 732 & 1538 & 785 & 1177 & 492 & 1246 & 407 & 994 & 383 & 1016 \\
\hline 14 & 358 & 2220 & 367 & 1842 & 632 & 1690 & 419 & 1311 & 399 & 1054 & 366 & 824 & 432 & 1637 \\
\hline 15 & 354 & 2380 & 375 & 1634 & 538 & 1852 & 327 & 1195 & 581 & 1140 & 417 & 727 & 430 & 7809 \\
\hline 16 & 359 & 1968 & 465 & 1818 & 517 & 1787 & 499 & 1428 & 253 & 713 & 274 & 834 & 280 & 1400 \\
\hline 17 & 394 & 1940 & 480 & 1827 & 495 & 1481 & 886 & 1727 & 509 & 1163 & 443 & 1140 & 489 & 1744 \\
\hline 18 & 296 & 2205 & 467 & 1800 & 603 & 1538 & 689 & 1721 & 543 & 1153 & 388 & 1191 & 603 & 2089 \\
\hline
\end{tabular}




\begin{tabular}{|c|c|c|c|c|c|c|c|c|c|c|c|c|c|c|}
\hline \multirow{2}{*}{ A } & \multicolumn{2}{|c|}{$|I|$} & \multicolumn{2}{|c|}{$|e|$} & \multicolumn{2}{|c|}{$|a|$} & \multicolumn{2}{|c|}{$|\Lambda|$} & \multicolumn{2}{|c|}{$|D|$} & \multicolumn{2}{|c|}{$|\mathrm{v}|$} & \multicolumn{2}{|c|}{$|\partial|$} \\
\hline & $\mathrm{F}_{1}$ & $\mathrm{~F}_{2}$ & $\mathrm{~F}_{1}$ & $\mathrm{~F}_{2}$ & $\mathrm{~F}_{1}$ & $\mathrm{~F}_{2}$ & $\mathrm{~F}_{1}$ & $\mathrm{~F}_{2}$ & $\mathrm{~F}_{1}$ & $\mathrm{~F}_{2}$ & $\mathrm{~F}_{1}$ & $\mathrm{~F}_{2}$ & $\mathrm{~F}_{1}$ & $\mathrm{~F}_{2}$ \\
\hline 19 & 298 & 2249 & 555 & 1749 & 770 & 1636 & 758 & 1384 & 368 & 1099 & 372 & 895 & 624 & 1830 \\
\hline 20 & 329 & 2203 & 489 & 1725 & 452 & 1486 & 568 & 1329 & 504 & 1224 & 361 & 752 & 668 & 1680 \\
\hline 21 & 359 & 1172 & 515 & 1890 & 431 & 1873 & 676 & 1291 & 382 & 1053 & 394 & 803 & 581 & 1723 \\
\hline 22 & 359 & 2185 & 412 & 2331 & 452 & 1529 & 716 & 1259 & 326 & 891 & 315 & 876 & 495 & 1744 \\
\hline 23 & 330 & 2325 & 576 & 1162 & 668 & 1809 & 579 & 1564 & 570 & 1150 & 354 & 764 & 646 & 1809 \\
\hline 24 & 317 & 2114 & 436 & 1948 & 942 & 1670 & 780 & 1394 & 531 & 771 & 346 & 933 & 397 & 1830 \\
\hline 25 & 338 & 2218 & 569 & 1791 & 560 & 1766 & 637 & 1410 & 562 & 786 & 453 & 965 & 388 & 1830 \\
\hline 26 & 360 & 2233 & 503 & 1474 & 689 & 1615 & 993 & 1715 & 506 & 1135 & 390 & 897 & 383 & 1787 \\
\hline 27 & 262 & 1489 & 465 & 1830 & 345 & 1916 & 702 & 1223 & 742 & 1070 & 469 & 934 & 646 & 1895 \\
\hline 28 & 302 & 1543 & 508 & 1626 & 814 & 1461 & 542 & 1334 & 263 & 1303 & 364 & 1103 & 350 & 1030 \\
\hline 29 & 270 & 1437 & 512 & 1614 & 732 & 1292 & 865 & 1338 & 262 & 1279 & 335 & 882 & 397 & 1314 \\
\hline 30 & 300 & 1718 & 615 & 1802 & 775 & 1658 & 796 & 1300 & 698 & 1078 & 397 & 1121 & 711 & 2046 \\
\hline 31 & 236 & 1592 & 592 & 2037 & 668 & 1852 & 827 & 1336 & 458 & 1235 & 449 & 1111 & 475 & 1787 \\
\hline 32 & 332 & 2367 & 610 & 1959 & 603 & 1530 & 472 & 1224 & 577 & 1408 & 504 & 1094 & 754 & 1960 \\
\hline 33 & 349 & 1996 & 517 & 1707 & 474 & 1464 & 526 & 1030 & 512 & 1214 & 338 & 819 & 301 & 1615 \\
\hline 34 & 332 & 1646 & 744 & 2072 & 646 & 1560 & 408 & 1392 & 502 & 1246 & 369 & 1390 & 511 & 1744 \\
\hline 35 & 426 & 1185 & 550 & 1289 & 861 & 1532 & 472 & 900 & 358 & 966 & 336 & 1046 & 380 & 1890 \\
\hline 36 & 318 & 1578 & 886 & 1823 & 747 & 1420 & 876 & 1362 & 490 & 944 & 420 & 824 & 377 & 1016 \\
\hline 37 & 308 & 2059 & 366 & 2039 & 431 & 1227 & 463 & 1512 & 590 & 1060 & 479 & 1087 & 517 & 1787 \\
\hline 38 & 316 & 1590 & 615 & 1869 & 760 & 1555 & 624 & 1200 & 420 & 1295 & 374 & 955 & 383 & 1003 \\
\hline 39 & 352 & 1899 & 619 & 2023 & 643 & 1787 & 637 & 1542 & 626 & 984 & 358 & 989 & 454 & 1744 \\
\hline 40 & 268 & 1969 & 433 & 2147 & 417 & 1205 & 380 & 1352 & 435 & 1240 & 388 & 1120 & 388 & 1916 \\
\hline $\bar{x}$ & 315 & 1914 & 499 & 1818 & 630 & 1571 & 642 & 1352 & 491 & 1116 & 386 & 955 & 492 & 1854 \\
\hline$\tilde{x}$ & 317.5 & 1968.5 & 497.5 & 1828.5 & 644.5 & 1557.5 & 637 & 1359.5 & 497 & 1117 & 373 & 923.5 & 466 & 1787 \\
\hline$\sigma_{x}$ & 44.18 & 355.34 & 108.48 & 253.62 & 155.05 & 182.65 & 177.87 & 200.36 & 122.16 & 190.37 & 58.69 & 157.01 & 132.20 & \begin{tabular}{|l|}
1023.86 \\
\end{tabular} \\
\hline$V x$ & 0.14 & 0.19 & 0.22 & 0.14 & 0.25 & 0.12 & 0.28 & 0.15 & 0.25 & 0.17 & 0.15 & 0.16 & 0.27 & 0.55 \\
\hline
\end{tabular}

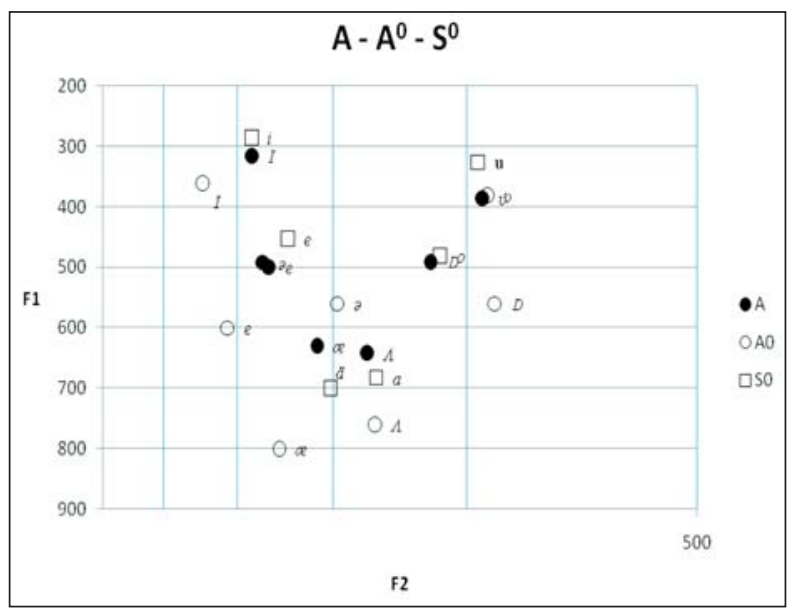

Fig. 2 Values $F_{1}$ a $F_{2}\left(A-A^{0}-S^{0}\right)$

\section{Conclusions}

In the experiment we applied the synthesis of the theoretical analysis and we detected the causal relations of the parameters by the statistical analysis of the variables. The consistency of repeated measurements of each text is verified by an adequate variance of measurements $\left(V_{x}\right)$. To provide the internal validity of measurements we used the statistical analysis of variance. To increase the external validity of measurements, i.e., to generalize the research results, we performed the experiment in fairly natural conditions - in the school environment and we used the research material reflecting natural communication.

Content validity results from the fact that the results of vocalic formant measurement of individual respondents represent an overall level of their pronunciation. The criteria validity was evaluated according to the correspondence of experimental analysis and the reference values of the phonemes. 
From the percipient's point of view, the auditive impression of a "good" or "bad" pronunciation is created by the complex of many subsegmental, segmental, plurisegmental and suprasegmental phonic phenomena. Some studies [e. g., 11] proved that the number of segmental substitutions highly correlates with marking the utterance as unidiomatic (non-native), though it does not mean that the substitutions are the only criterion. They are probably perceived and identified very easily, but the listener's impression of one's pronunciation is created by the complex of many interrelated factors [22].

\section{References}

[1] CORDER, P. S.: The Significance of Learner's Errors, IRAL, No. 4, pp. 161-170, 1967.

[2] SELINKER, L.: Language Transfer, General Linguistics, No. 2, pp. 67-92, 1969.

[3] SELINKER, L.: Interlanguage, IRAL, No. 3, pp. 209-231, 1972.

[4] NEMSER, W.: Approximative Systems of Foreign Language Learners, IRAL, No 2, pp. 115-123, 1971.

[5] RICHARDS, J.: Error Analysis and Second Language Strategies, Language Sciences, No. 17, pp. 12-22, 1971,

[6] CORDER, P. S.: Idiosyncratic Dialects and Error Analysis, IRAL, No. 2, pp. 147-160, 1971.

[7] COOK, V.: Second Language Learning and Language Teaching, London : Edward Arnold, 1991.

[8] HRDLICKA, M. To the Problems of Foreign Language Code Acquisition, Casopis pro moderni filologii, No. 1, pp. 36-43, 2004.

[9] FLEGE, J. E.: Phonetic Interference in Second Language Acquisition, Bloomington : Indiana University, 1979.

[10] GONDOVA, D.: Using Activities as a Way of Proceduralization of Learners' Language Knowledge, Communications. Scientific Letters of the University of Zilina, Vol. 12, 2010, No. 3, pp. 30-34.

[11] MALA, E.: Influence of English on the Slovak Language, In: Inonarodne sociokulturne fenomeny a cudzojazycne vzdelavanie. Nitra: FEM SPU, 2004.

[12] FLEGE, J. E.: The Phonological Basis of Foreign Accent: A Hypothesis, TESOL Quarterly, No. 4, pp. 443-455, 1981.

[13] FLEGE, J. E., HILLENBRANDT, J. 1984. Limits on Pronunciation Accuracy in Adult Foreign Language Speech Production, $J$. of the Acoustical Society of America, No. 3, pp. 708-721.

[14] FLEGE, J. E.: The production of "new" and "similar" phones in a foreign language: Evidence for the effect of equivalence classification, Journal of Phonetics, No. 1, pp. 47-65, 1987.

[15] ASHER, J. J., GARCIA, R.: The optimal age to learn a second language, The Modern Language Journal, n. 5, pp. 334-341, 1969.

[16] DICKERSON, L. J.: Internal and External Patterning of Phonological Variability in the Speech of Japanese Learners of English: Toward a Theory of Second-language Acquisition, Chicago: University of Illinois, 1974.

[17] WEINREICH, U.: Languages in Contact, New York : Linguistic Circle of New York, 1953.

[18] GIMSON, A. C. An Introduction to the Pronunciation of English, Newcastle upon Tyne : Athenaeum Press, 1989.

[19] KRAL, A., SABOL, J.: Phonetics and Phonology (in Slovak), Bratislava: Slovenske pedagogicke nakladatelstvo, 1989.

[20] Council for Cultural Co-operation: Common European Framework of Reference for Languages, Olomouc: Univerzita Palackeho, 2002.

[21] SABOL, J., ZIMMERMANN, J.: Statistics. Exact methods in Linguistics and Literary Science (in Slovak), Presov : Filozoficka fakulta UPJS Presov, 1986.

[22] LELAKOVA, E.: Application of Field and Matrix Theory on Lexico-semantic Analysis of English Nouns of Happiness, J. of Interdisciplinary Philogy, Vol. 1, 2010, No. 2, pp. 19-46. 